Tropical Journal of Pharmaceutical Research September 2021; 20 (9): 1915-1923

ISSN: $1596-5996$ (print); 1596-9827 (electronic)

(C) Pharmacotherapy Group, Faculty of Pharmacy, University of Benin, Benin City, 300001 Nigeria.

\title{
Synergistic anti-atherosclerotic effect of Yerba Maté (IIlex Paraguariensis) polyphenols and Lox-1 silencing in foam cell model
}

\author{
Shao-Hong $\mathrm{Yu}^{1,2}$, Hui $\mathrm{Fu}^{3}$, Yan-Yan Yin ${ }^{4}$, Zhao-Di Yue ${ }^{4}$, Yi-Bo Liu ${ }^{4}$, Ren-Jie \\ Zhao ${ }^{4}$, Bing-Yu Du ${ }^{4}$, Shin-Da Lee ${ }^{4,5 *}$ \\ ${ }^{1}$ Department of rehabilitation medicine, The Second Affiliated Hospital of Shandong University of Traditional Chinese Medicine, \\ Jinan, 250001, PR China, ${ }^{2}$ The Second Clinical Medical College, Shandong University of Traditional Chinese Medicine, Jinan, \\ 250001, PR China, ${ }^{3}$ The Clinical Medical College, Cheeloo Medical College of Shandong University, Jinan, 250012, PR \\ China, ${ }^{4}$ College of Rehabilitation Medicine, Shandong University of Traditional Chinese Medicine, Jinan, 250014, PR China, \\ ${ }^{5}$ Department of Physical Therapy, Asia University, Taichung, Taiwan
}

*For correspondence: Email: sutcm2006@163.com

\begin{abstract}
Purpose: To elucidate the anti-atherosclerotic effect of Yerba Mate polyphenols (MP) as well as the anti-atherosclerotic effect of a combination of MP and silencing of lectin-like oxidized low-density lipoprotein receptor-1 interference group (LOX)-1.

Methods: The anti-atherosclerotic effects of control group (CG), simvastatin group (SG), MP group (MP), LOX-1 interference group (LOX) and MP + LOX-1 interference group (MP-LOX) were determined using Oil Red O staining, enzyme-linked immunosorbent assay (ELISA) and Western blot assay.

Results: The levels of foam cells, intracellular lipids, viz, total cholesterol (TC), free cholesterol (FC), cholesterol ester (CE) and acyl-coenzyme A: cholesterol acyltransferase 1 (ACAT1); LOX-1, inflammation (TNF-alpha, IL-6 and pNF-KB/NF-KB); adhesion molecular status (ICAM-1 and VCAM-1), and monocyte chemotactic protein-1 in SG and in MP, LOX and MP-LOX groups were significantly decreased, when compared with CG $(p<0.01)$. The levels of these parameters were much lower in MP$L O X$ group than in SG $(p<0.01)$. However, they were synergistically reduced in MP-LOX group, relative to MP group or LOX group $(p<0.01)$. Combination of LOX-1 gene silencing with MP produced synergistic anti-atherosclerotic effect which was reflected in decreases in foam cell formation, intracellular lipids, inflammatory status, adhesion molecular status, and MCP-1-mediated migration and infiltration of macrophages in foam cells.

Conclusion: The synergistic anti-atherosclerotic effects of MP and LOX-1 gene silencing may be potential tools for development of anti-atherosclerotic agents.
\end{abstract}

Keywords: Atherosclerosis, Adhesion, Inflammatory, Lipid accumulation, Ilex paraguariensis

This is an Open Access article that uses a funding model which does not charge readers or their institutions for access and distributed under the terms of the Creative Commons Attribution License (http://creativecommons.org/licenses/by/4.0) and the Budapest Open Access Initiative (http://www.budapestopenaccessinitiative.org/read), which permit unrestricted use, distribution, and reproduction in any medium, provided the original work is properly credited.

Tropical Journal of Pharmaceutical Research is indexed by Science Citation Index (SciSearch), Scopus, International Pharmaceutical Abstract, Chemical Abstracts, Embase, Index Copernicus, EBSCO, African Index Medicus, JournalSeek, Journal Citation Reports/Science Edition, Directory of Open Access Journals (DOAJ), African Journal Online, Bioline International, Open-J-Gate and Pharmacy Abstracts

\section{INTRODUCTION}

Macrophage-derived foam cells (MFC) which are chief cellular components of atherosclerotic plaques, are involved in two major pathogenic processes in atherogenesis: cholesterol buildup and inflammatory status [1,2]. Lipid droplets (LD) are the major sites of cholesterol storage in 
macrophage foam cells [3]. Increased influx and esterification of cholesterol, and decreased efflux of cholesterol result in increased accumulation of cellular cholesterol esters (CEs) [4]. When the cholesterol esters (CEs) accumulate in large amounts, they are stored as cytoplasmic lipid droplets, leading to the formation of macrophagederived foam cells [5]. Acyl-Coenzyme A: cholesterol acyltransferase 1 (ACAT1) is an intracellular enzyme that converts free cholesterol (FC) into cholesteryl esters (CE) for storage in lipid droplets, and it promotes foam cell formation in atherosclerotic lesions $[5,6]$.

Tumor necrosis factor-alpha (TNF- $\alpha$ ) and interleukin-6 (IL-6) are two important proatherosclerotic cytokines, in which TNF- $\alpha$ enhances macrophage foam cell formation by inhibiting intracellular lipid catabolism [7]. Intercellular cell adhesion molecule-1(ICAM-1) and vascular cell adhesion molecule-I (VCAM-1) may mediate the intimal accumulation of macrophages [8]. Monocyte chemotactic protein (MCP-1) is a crucial proinflammatory factor that contributes to the development of atherosclerotic lesions [9]. Activation of nuclear factor-kappa $B$ (NF-KB) induces the synthesis and release of various atherosclerosis-related proteins such as inflammatory factors, adhesion molecules, and chemokines [10]. Based on the aforementioned mechanism, inflammatory status and lipid dysregulation are the key steps in the formation and development of foam cells.

Yerba Mate tea (leaves of the tree llex paraguariensis) is believed to be a natural source of cardioprotective, lipid-lowering and antioxidant compounds [11-13]. Polyphenols are the main bioactive principles of Yerba Mate. Previous studies have demonstrated that Yerba Mate polyphenols (MPs) lower blood lipid levels in people with abnormal blood lipids, and in animal models $[14,15]$. Simvastatin is often used to treat hypercholesterolemia, and it is effective in improving lipid profiles and reducing plasma levels of inflammatory markers. However, several studies have shown that simvastatin therapy is associated with harmful side effects $[16,17]$. It is still unknown whether MP inhibits foam cell formation in atherosclerosis, nor are the molecules and signaling pathways involved known.

Lectin-like oxidized low-density lipoprotein receptor-1 (LOX-1) serves as a receptor for oxidized low-density lipoprotein (ox-LDL) [18]. The LOX-1 expressed on macrophages inhibits macrophage migration and stimulates foam cell formation, which plays a critical role in ox-LDLmediated atherosclerosis [19]. Moreover, LOX-1 initiates a vicious cycle from activation of proinflammatory signaling pathways, thereby enhancing formation of reactive oxygen species and secretion of pro-inflammatory cytokines [20].

The present study was carried out to investigate the anti-atherosclerotic effect of MP and the antiatherosclerotic effects of combination of MP and LOX-1 silencing. In the first stage, the effect of MP extract on foam cell model was studied. Then, the LOX-1 gene lentivirus interference vector was constructed, followed by determination of the influence of LOX-1 gene interference and MP on macrophage lipid metabolism and the expression levels of inflammation-related genes induced by ox-LDL.

\section{EXPERIMENTAL}

\section{Foam cell culture}

Human monocytic leukemia cell line ( $\mathrm{TH}-1)$ was used to establish a cell model of foam cell formation induced by phorbol-12-myristate-13acetate (PMA) and ox-LDL. The $\mathrm{TH}-1$ cells were purchased from Cell Bank of Shanghai Institute of Biochemistry and Cell Biology (320 Yue Yang Road, Shanghai 200031, PR China). The PMA (100 nmol/L) was added to human THP-1 cell culture medium for $48 \mathrm{~h}$ to induce the formation of macrophages. The macrophages were then incubated with ox-LDL $(50 \mu \mathrm{g} / \mathrm{MI})$ for $24 \mathrm{~h}$ to generate foam cells.

\section{Lentivirus-mediated LOX-1 interference}

The LOX-1 gene sequence was searched in GenBank (https://www.ncbi.nlm.nih.gov/,Gl: NM_001172632.1). The specific RNAi sequences targeted at human LOX-1 gene were designed using RNA interference design software (Ambion Company, Naugatuck, CT, USA). The designed siRNA was synthesized by Generay Biotech Co. Ltd (Shanghai, China). The synthesized single-stranded DNA formed doublestranded DNA oligonucleotide sequences after annealing. The linearized pLKO.1-EGFP-C1 vector was linked by Agel I and Ecol I enzyme digestion. The linearized vector was ligated with annealing shRNA, and then LOX-1 gene targeted shRNA lentivirus expression vector was constructed.

Thereafter, liposome-mediated transfection of 293T cells (packaging cells) was used to assemble pLKO.1-shLOX-1, psPAX2 and pMD2G as a complete retrovirus lentivirus particle. The 293T cells (for virus packaging) were purchased from American Type Culture Collection (ATCC, Manassas, VA, USA). 
Recombinant lentivirus vector-transfected 293T cells showed that the LOX-1 protein was significantly reduced and LOX-1 lentivirus interference vector was successfully constructed.

\section{Cell grouping and treatment}

To investigate the effect of MP and LOX-1 gene silencing on ox-LDL-induced macrophage foam cell formation, ox-LDL was used to induce THP-1 cells to form foam cells in all groups. Samples of Yerba Mate tea were purchased from Las Marias Ltd. (Ruta Nacional, Gdor Virasoro Corrientes, Argentina). Macro-porous resin separation method was used for purification of the extract for obtaining MP [21]. Macrophage-derived foam cells were randomly divided into five sub-groups $(n=6)$ : CG which received ultra-pure water; simvastatin group (SG) treated with $100 \mu \mathrm{g} / \mathrm{mL}$ simvastatin; MP group treated with $200 \mu \mathrm{g} / \mathrm{mL}$ MP; LOX-1 interference group (LOX) treated with LOX-1 gene lentivirus interference vector, and MP + LOX-1 intervention group (MP-LOX) treated with $200 \mu \mathrm{g} / \mathrm{mL}$ MP and LOX-1 gene lentivirus interference vector.

After $24 \mathrm{~h}$ of culture, the cells were harvested and analyzed for intracellular lipid levels, including total cholesterol (TC), free cholesterol (FC0, cholesteryl ester (CE), ACAT1 and expression levels of damage response factors. Recombinant lentivirus vector-transfected 293T cells had significantly attenuated expression of LOX-1 protein, indicating that the LOX-1 lentivirus interference vector was successfully constructed.

\section{Oil Red $O$ staining assay}

Lipid droplets in foam cells were observed with Oil Red O staining. The slides of foam cells were washed three times with phosphate buffer saline (PBS), and traces of water were blotted, followed by fixation in $10 \%$ neutral formaldehyde for 10 min, and Oil Red $O$ staining for $10 \mathrm{~min}$. The slides were decolorized with $60 \%$ isopropanol, and excessive dye was washed off. Then, the slides were washed three times with PBS, followed by counterstaining with hematoxylin for 5 min, color separation with $1 \% \mathrm{HCl}$, bluing with ammonia, and mounting with gelatin glycerin. Finally, the slides were examined, photographed and recorded in a x200 field and x800 field under cx41 microscope (XDS-500C, Shanghai Caikang Optical Instrument Co. Ltd, PR China). Image J software program was used to detect and quantify foam cells stained with Oil Red $\mathrm{O}$.

The percentage of foam cells was determined in terms of the relative number of cells that contained three or more fatty droplets in each field of view. A minimum of 3 fields of view were used for each experimental point. Data from six separate experiments were averaged, and each experiment had three points.

\section{ELISA}

Cells in each group were centrifuged at $1500 \mathrm{rpm}$ at $4{ }^{\circ} \mathrm{C}$ for $10 \mathrm{~min}$ after $24 \mathrm{~h}$ of incubation. The concentrations of TC, FC, CE, ACAT1, TNF- $\alpha$, IL-6, ICAM-1, VCAM-1 and MCP-1 in the supernatant of each group were determined using enzyme-linked immunosorbent assay (ELISA) with human ELISA kit (Wuhan Colorful Gene Biotech Company, Hubei, China), according to the manufacturer's instructions. The absorbance of each well was read at $450 \mathrm{~nm}$ using a trace orifice spectrophotometer. A standard curve was drawn using data produced from diluted standard solutions with curve expert 1.3. The concentrations of TC, FC, CE, ACAT1, TNF- $\alpha$, IL-6, ICAM-1, VCAM-1 and MCP-1 were calculated from the standard curve. All assays were independently repeated six times.

\section{Western blot analysis}

Total protein was extracted from cells in each group using RIPA lysis buffer. Protein concentration was determined with BCA method.

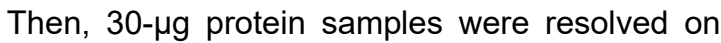
SDS-polyacrylamide gel electrophoresis and transferred to PVDF membranes. The membranes were incubated in blocking buffer for $1 \mathrm{~h}$ at room temperature and then immunoblotted with diluted primary antibodies against LOX-1 (1:1000), glyceraldehyde-3-phosphate dehydrogenase (GAPDH) (1:1500), pNF-kB (1:800) and NF-KB $(1: 1000)$ for $12 \mathrm{~h}$.

This was followed by incubation with HRPlabeled secondary antibody $(1: 1000)$ at room temperature for $1 \mathrm{~h}$, and washing of the membranes using TBST. Thereafter, the bands were developed with enhanced chemiluminescence (ECL) and exposed in a dark room. The gray value ratio of $L O X-1$ and $p N F-k B / N F-k B$ were used to indicate the relative protein expression levels of LOX-1 and NF-KB, with GAPDH as internal standard.

\section{Statistical analysis}

Statistical analysis was performed with SPSS 19.0 (IBM, Chicago, USA). All data are expressed as mean \pm standard error of the mean (SEM). Comparison among multiple groups was performed using LSD analysis. Values of $p<$ 
0.05 were taken as indicative of significant differences.

\section{RESULTS}

\section{Lipid droplets in foam cells}

Results from Oil Red O staining showed that the PMA- and ox-LDL-induced foam cell formations were successfully established in CG. Macrophages were enlarged in size, and cytoplasm was loose and increased in size in CG. Numerous deep red-stained lipid droplets were present in cytoplasm, and the lipid content exceeded $60 \%$ in most cells, indicating that the foam cell model was successfully established in CG. Intracellular lipid droplets, red granules and percentage of foam cells in SG, as well as MP, LOX and MP-LOX groups were significantly reduced, when compared to corresponding values in CG $(p<0.01)$. In CG group, foam cells comprised $85.95 \pm 3.87 \%$ of total cells, while the percentages of foam cells in SG, and MP, LOX and MP-LOX groups were $55.88 \pm 4.1,58.82 \pm$ $3.92,50.5 \pm 3.21$ and $33.28 \pm 4.66$, respectively. There were no significant differences in the percentage of foam cells between SG and MP group $(p>0.05)$. Intracellular lipid droplets, red granules and the percentage of foam cells in MP. LOX group were synergistically reduced, when compared to MP group or LOX group (Figures $1 \mathrm{~A}-1 \mathrm{C})$. The results imply that LOX-1 protein expression was reduced by MP intervention or LOX-1 gene silencing, and the combination of these two resulted in synergistic effects.

\section{Intracellular lipid assessment}

The levels of intracellular lipids in SG, as well as MP, LOX and MP-LOX groups were reduced, when compared to CG. The levels of TC, FC, CE and ACAT1 in SG, and MP, LOX or MP-LOX groups were significantly decreased, relative to the CG $(p<0.01)$. The reductions in levels of TC , CE and ACAT1 in MP group were less than those in SG group $(p<0.01)$, whereas the reduction in FC was similar in SG and MP group $(p>0.05)$. The levels of TC, FC, CE and in MPLOX group were synergistically reduced, when compared to MP group or LOX group ( $p<0.01)$.
These results are shown in Table 1 . The results imply that MP and LOX-1 gene silencing inhibited the expression of ACAT1, resulting in lower accumulation of $\mathrm{CE}$ in macrophages, reduced intracellular lipids and lower cholesterol level, while increasing cholesterol esterification and inhibiting MFC formation.

\section{LOX-1 protein expression}

To determine the protein products of LOX-1, the expressions of LOX-1 in foam cells in all groups were measured using Western blot analysis. The relative expressions of LOX-1 in SG, and in MP, LOX and MP-LOX groups were reduced, when compared to CG. There was higher level of LOX1 in MP than in SG, which implies that the reduction in LOX-1 in MP group was less than that in SG group $(p<0.01)$.
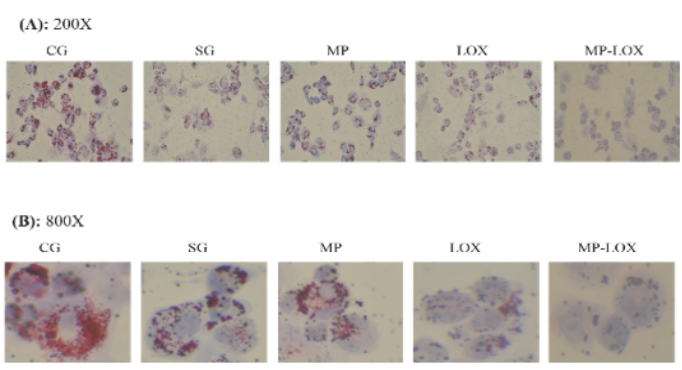

(C)

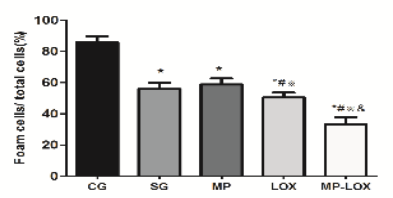

Figure 1: Lipid droplets in foam cells with Oil Red $O$ staining. There were 5 groups in PMA/ox-LDL-induced foam cell culture: CG, SG, MP, LOX, and MP-LOX. (A) The lipid droplets in foam cells were observed in the 5 groups at $\times 200$ field under a microscope after Oil Red $O$ staining. (B) Intracellular red granules at $x 800$ field under microscope in the five groups. (C)The bars represent percentage of foam cells. Each experiment was performed six times with triplicate of every experimental control point. Data are presented as mean \pm SE. ${ }^{*} p<0.01$, compared with CG group; ${ }^{\#} p<$ 0.01 , compared with SG group; $* p<0.01$, compared with MP group; ${ }^{*} p<0.01$, compared with LOX group

Table 1: Intracellular lipids

\begin{tabular}{|c|c|c|c|c|c|}
\hline Group & CG & SG & MP & LOX & MP-LOX \\
\hline $\mathrm{TC}(\mathrm{nmol} / \mathrm{mL})$ & $49.8 \pm 1.1$ & $36.3 \pm 0.8^{*}$ & $38.2 \pm 1.3^{* \#}$ & $32.3 \pm 4.5^{\star \# ※ ~}$ & $27.4 \pm 0.8^{\star \# ※ \&}$ \\
\hline $\mathrm{FC}(\mathrm{nmol} / \mathrm{mL})$ & $21.6 \pm 0.1$ & $12.9 \pm 0.2^{*}$ & $12.2 \pm 0.2^{*}$ & $14.2 \pm 0.4^{\star \# \approx}$ & $10.4 \pm 0.2^{* \# \approx \&}$ \\
\hline $\mathrm{CE}(\mathrm{nmol} / \mathrm{mL})$ & $42.2 \pm 1.2$ & $20.5 \pm 0.8^{*}$ & $28.0 \pm 1.3^{\star \#}$ & $26.1 \pm 4.7^{\text {«\# }}$ & $17.4 \pm 1.1^{\text {*\#※\& }}$ \\
\hline ACAT1 (U/L) & $192 \pm 8$ & $94 \pm 15^{*}$ & $156 \pm 6$ *\# & $130 \pm 15^{\star \# ※}$ & $65 \pm 9 * \# ※ \&$ \\
\hline
\end{tabular}


Values are mean \pm SE ( $n=6$ for each group). There were 5 groups in PMA/ox-LDL-induced foam cell culture: CG, SG, MP, LOX, and MP-LOX. ${ }^{*} p<0.01$, compared to CG group; ${ }^{*} p<0.01$, compared to SG group; ${ }^{*} p<$ 0.01 , compared to MP group; ${ }^{\&} p<0.01$, compared to LOX group

The relative expression level of LOX-1 in MPLOX group was synergistically reduced, when compared to MP group or LOX group $(p<0.01)$ (Figure 2). These results suggest that LOX-1 gene silencing in combination with MP, produced synergistic effect on LOX-1 levels.

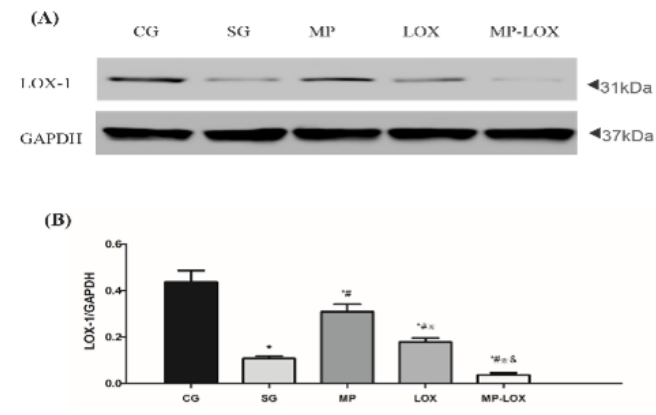

Figure 2: LOX-1 protein expression by western blot. The 5 groups in PMA/ox-LDL-induced foam cell culture were CG, SG, MP, LOX, and MP-LOX. (A) Representative protein products of LOX-1 extracted from foam cells in the 5 groups were measured with Western blot analysis, with GAPDH serve as internal control. (B) Bars representing the relative protein expression of LOX-1. Data presented as mean \pm SE. ${ }^{*} p<0.01$, compared with CG group; ${ }^{*} p<0.01$, compared with SG group; $\aleph_{p}<0.01$, compared with MP group; ${ }^{\&} p<0.01$, compared with LOX group

\section{Inflammatory status}

To investigate inflammatory status in each group, the expressions of TNF- $\alpha$ and IL- 6 in each group were assayed with ELISA, while pNF-kB/NF-kB was determined with Western blot analysis. The levels of TNF- $\alpha$ and IL-6 (Table 2) and pNF$\mathrm{kB} / \mathrm{NF}-\mathrm{kB}$ (Figure 3) in SG, MP, LOX and MPLOX groups were significantly decreased, when compared with their levels in CG $(p<0.01)$. The levels of TNF- $\alpha$ and IL-6 (Table 2) as well as pNF-kB/NF-kB were higher in MP than in SG (Figure 3), implying that the reductions in TNF-a and IL-6 inflammatory status in MP group were less than those in SG group $(p<0.01)$ (Table 2). The levels of TNF- $\alpha$ and IL- 6 (Table 2) as well as pNF-kB/NF-kB (Figure 3) in MP-LOX group were synergistically reduced, when compared with the corresponding values in MP group or LOX group. These results suggest that LOX-1 the combination of gene silencing with MP produced synergistic anti-inflammatory effects in foam cells.

\section{Adhesion molecular status}

Compared to CG, all intervention groups had reduced levels of the adhesion molecules ICAM-
1 and VCAM-1. The levels of ICAM-1 and VCAM-1 in SG, MP, LOX and MP-LOX groups were significantly decreased, when compared with CG $(p<0.01)$. The levels of ICAM-1 and VCAM-1 were higher in MP than in SG, which implies that the reductions in ICAM-1 and VCAM1 status in MP group were less than those in SG $(p<0.01)$ (Table 2). The levels of ICAM-1 and VCAM-1 in MP-LOX group were synergistically reduced, when compared to MP group or LOX group. These results imply that combination of LOX-1 gene silencing with MP produced synergistic effects on adhesion status of foam cells.
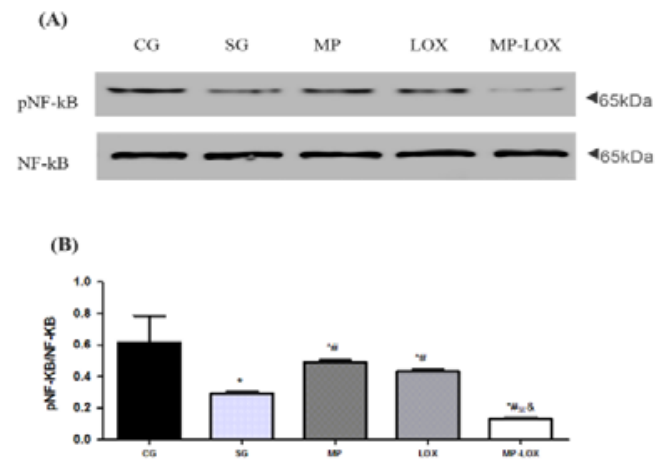

Figure 3: NF-kB protein expression levels in 5 groups of PMA/ox-LDL-induced foam cell culture: CG, SG, MP, LOX, and MP-LOX. (A) Representative protein expressions of pNF-KB and NF-KB from foam cells in the 5 groups, as measured using Western blot analysis. (B) The bars represent relative protein quantification of pNF- $\kappa \mathrm{B} / \mathrm{NF}-\kappa \mathrm{B}$. Data presented as mean \pm SE. ${ }^{*} p<0.01$, compared with CG group; ${ }^{*} p<$ 0.01 , compared with SG group; $* p<0.01$, compared with MP group; ${ }^{\star} p<0.01$, compared with LOX group

\section{Chemokine profiles}

The levels of MCP-1 in SG, and in MP, LOX and MP-LOX groups were significantly decreased, relative to CG ( $p<0.01$; Table 2$)$. The level of MCP-1 was higher in MP than in SG, which implies that the reduction in MCP-1 in MP group was less than that in SG $(p<0.01)$. The levels of ICAM-1 and VCAM-1 in MP-LOX group were synergistically reduced, compared to MP group or LOX group. These results indicate that combination of LOX-1 gene silencing with MP produced synergistic effects on MCP-1-mediated migration and infiltration of macrophages in foam cells.

\section{DISCUSSION}

In the present study, the effect of MP on the formation of foam cells, and the co-anti-athero- 
Table 2: Intracellular damage response factors in the 5 groups of PMA/ox-LDL-induced foam cell culture: CG, SG, MP, LOX, and MP-LOX

\begin{tabular}{|c|c|c|c|c|c|}
\hline Group & $\overline{C G}$ & SG & MP & LOX & MP-LOX \\
\hline \multicolumn{6}{|c|}{ Inflammatory status } \\
\hline TNF- $\alpha(p g / m l)$ & $388 \pm 11$ & $218 \pm 15^{\star}$ & $320 \pm 4 * \#$ & $261 \pm 4^{\star \# ※}$ & $171 \pm 12^{\star \# ※ \&}$ \\
\hline IL-6 (ng/L) & $83.1 \pm 2.5$ & $53.2 \pm 2.6^{*}$ & $74.9 \pm 2.9^{* \#}$ & $61.5 \pm 3.3^{\text {*\# }}$ & $44.6 \pm 1.8^{* \# \approx \&}$ \\
\hline \multicolumn{6}{|c|}{ Adhesion molecule status } \\
\hline ICAM-1 (ng/L) & $449 \pm 27$ & $268 \pm 45^{*}$ & $383 \pm 3^{* \#}$ & $316 \pm 3^{* \# *}$ & $193 \pm 4^{* \# \approx \&}$ \\
\hline VCAM-1 (ng/L) & $36.5 \pm 0.2$ & $23.0 \pm 0.3^{*}$ & $31.4 \pm 0.3^{* \#}$ & $24.5 \pm 1.6^{\star \# ※}$ & $20.4 \pm 1.4^{\star \# ※ \&}$ \\
\hline $\begin{array}{l}\text { Chemokines } \\
\text { MCP-1 (ng/L) }\end{array}$ & $576 \pm 3$ & $347 \pm 21^{*}$ & $538 \pm 30^{* \#}$ & $431 \pm 27^{\star \# ※}$ & $283 \pm 18^{* \# ※ \&}$ \\
\hline
\end{tabular}

Values are mean \pm SE ( $n=6$ for each group). ELISA = enzyme-linked immunosorbent assay; TNF- $\alpha=$ tumor necrosis factor $\alpha$; IL-6 = interleukin 6 ; ICAM-1 = intercellular cell adhesion molecule-1; VCAM-1 = vascular cell adhesion molecule-l; MCP-1 = monocyte chemotactic protein-1. ${ }^{*} p<0.01$, compared with CG; ${ }^{*} p<0.01$, compared with SG; * $p<0.01$, compared with MP group; ${ }^{*} p<0.01$, compared with LOX group

sclerotic effect of MP and silencing LOX-1 gene, were investigated.

The results showed that MP intervention alone, and LOX-1 gene silencing alone, as well as combination of MP with LOX-1 gene silencing, all inhibited foam cell formation and LOX-1 expression. Moreover, they reduced intracellular levels of TC, FC, CE and ACAT1); decreased inflammatory status (TNF- $\alpha$, IL- 6 and pNF$\mathrm{KB} / \mathrm{NF}-\mathrm{KB}$ ), and reduced adhesion molecular status (ICAM-1 and VCAM-1), and MCP-1. These results indicate that the combination of MP and LOX-1 gene silencing may have pleiotropic anti-atherosclerotic synergistic effects that prevent or delay the progression of atherosclerosis. It has been reported that LOX-1 enhances vascular endothelial injury, lipid accumulation, and pro-inflammatory status in early atherosclerosis [22].

Therefore, LOX-1 gene silencing seems to be a key target that can be blocked so as to inhibit the uptake of ox-LDL by macrophages, thereby preventing the formation of foam cells. In the early stage of foam cell formation, the combination of LOX-1 with ox-LDL specifically results in unlimited uptake of ox-LDL and intracellular accumulation of a large amount of cholesterol and triglycerides. Ultimately, the cells are transformed into foam cells, followed by the formation of fatty streak [23].

This study has provided evidence showing that LOX-1 protein expression is reduced by MP or LOX-1 gene silencing. The combination of MP and LOX-1 gene silencing synergistically reduced LOX-1 protein expression. These findings suggest that MP prevents foam cell formation synergistically through decreased LOX-1, and that LOX-1 inhibition may retard atherosclerosis. Therefore, there is a certain interaction between the LOX-1 gene silencing and MP-induced beneficial synergistic effects on
LOX-1 and foam cell formation in atherosclerosis. Increased levels of intracellular lipid droplets, TC, FC, CE, ACAT1 were observed in PMA/ox-LDL-induced foam cell culture. These increases were attenuated by MP or LOX-1 gene lentivirus interference vector. The combination of MP and LOX-1 gene silencing synergistically and markedly inhibited foam cells formation and reduced intracellular lipid accumulation.

After uptake of ox-LDL by macrophages, cholesteryl esters are hydrolyzed into free cholesterol and fatty acids. The free cholesterol is esterified again under the action of ACAT1, and then stored in the cells [24]. Accumulation of a large amount of cholesteryl ester in macrophages is the key factor in atherosclerotic plaque formation [25]. In this study, MP and LOX-1 gene silencing appeared to synergistically inhibit intracellular lipid accumulation by decreasing ACAT1. The findings further support the potential link amongst MP, LOX-1, and intracellular lipids.

Inflammatory reaction is the basic pathological character of atherosclerosis and the key to its prevention. On the one hand, ox-LDL activates numerous inflammatory factors and promotes inflammatory cell infiltration. On the other hand, activated macrophage cytophagy and degraded ox-LDL lead to the accumulation of cholesterol and formation of foam cells $[26,27]$. These data suggest that TNF- $\alpha$ and IL- 6 were enhanced during foam cell formation, but this effect was reversed synergistically by MP and LOX-1 gene silencing, indicating that LOX-1 inhibition and MP intervention could synergistically and markedly suppress foam cell formation.

Activated endothelial NF-KB signaling plays an important role in foam cell formation and promotes macrophage recruitment to atherosclerotic plaques. The data obtained in this 
study suggest that MP and LOX-1 gene silencing could synergistically inhibit the transcriptional activity of NF-KB and its downstream factors.

Focal recruitment of monocytes is part of the earliest detectable cellular responses in atherosclerosis. The adhesion molecules ICAM-1 and VCAM-1 may enhance the movement of monocytes from blood circulation into intima, and promote the accumulation of lipids and foam on the arterial vascular wall [28]. In this study, in the PMA/ox-LDL-induced foam cells model, ICAM-1 and VCAM-1 were significantly increased. However, LOX-1 gene silencing and MP intervention synergistically and markedly reduced the levels of ICAM-1 and VCAM-1 in foam cells. Therefore, these findings imply that the combination of MP with LOX-1 gene silencing may decrease monocyte accumulation.

Studies have shown that MCP-1 attracts monocytes to the inflammatory sites of vascular subendothelial space via chemotaxis, thereby initiating the migration of monocytes into the arterial wall to form excessive amounts of macrophage-derived foam cells [29,30]. Along with macrophages, MCP-1 influences the growth of other cell types within the atherosclerotic lesion. In this study, MP and LOX-1 gene silencing synergistically and markedly inhibited MCP-1, implying that the combination of MP with LOX-1 gene silencing inhibited the migration of monocytes towards endothelium, as well as the formation of foam cells.

The limitations of this study are as follows: In the first place, this study investigated the effect of combination of MP and LOX-1 gene silencing only in a foam cell model. An animal model was not used. Therefore, there is need for the use of an animal model, as well as clinical application of combination of MP with LOX-1 downregulation in subsequent studies. Secondly, the underlying mechanism of synergistic effects of MP and LOX-1 silencing are still unclear. There is need to unravel this binding site or interaction between MP and LOX-1 because it may be a key target for treating or preventing foam cell formation.

\section{CONCLUSION}

The most important new finding in this study is that MP and LOX-1 gene silencing synergistically and markedly reduce foam cell formation, LOX-1 expression, intracellular lipids, inflammatory status, adhesion molecular status, and monocyte chemotactic protein-1. This is the first study on the synergistic effect of MP and LOX-1 gene silencing on foam cell formation. The synergistic anti-atherosclerotic effects of LOX-1 gene silencing and MP have a potential to be developed into a therapy for atherosclerosis.

\section{DECLARATIONS}

\section{Acknowledgement}

This study was supported by grants from the Science and Technology Plan of University in Shandong Province (no. J16LK09), the Medical Health Technology Development Project of Shandong Province (no. 2018WS201), the Shandong Province Colleges and Universities Outstanding Young Teachers in Domestic Visiting Scholars Project at the Capital Medical University, and the National Key Research and Development Project (no. 2018YFC1706005). The funders had no role in study design, data collection, and analysis, or in preparation of the manuscript.

\section{Conflict of interest}

No conflict of interest is associated with this work.

\section{Contribution of authors}

We declare that this work was done by the authors named in this article and all liabilities pertaining to claims relating to the content of this article will be borne by the authors. Shao-Hong Yu and Hui are co-first authors.

\section{Open Access}

This is an Open Access article that uses a funding model which does not charge readers or their institutions for access and distributed under the terms of the Creative Commons Attribution License (http://creativecommons.org/licenses/by/ 4.0) and the Budapest Open Access Initiative (http://www.budapestopenaccessinitiative.org/rea d), which permit unrestricted use, distribution, and reproduction in any medium, provided the original work is properly credited.

\section{REFERENCES}

1. Park S, Ahn JW, Jo Y, Kang HY, Kim HJ, Cheon Y, Kim JW, Park Y, Lee S, Park K. Label-Free Tomographic Imaging of Lipid Droplets in Foam Cells for MachineLearning-Assisted Therapeutic Evaluation of Targeted Nanodrugs. ACS Nano, 2020, 14(2): 1856-1865.

2. Li L, Du Z, Rong B, Zhao D, Wang A, Xu Y, Zhang H, Bai $X$, Zhong J. Foam cells promote atherosclerosis 
progression by releasing CXCL12. Biosci Rep, 2020, 40(1): BSR20193267.

3. Plakkal Ayyappan J, Paul A, Goo YH. Lipid dropletassociated proteins in atherosclerosis (Review). Mol Med Rep, 2016, 13(6): 4527-4534.

4. Eguchi $K$, Kato $H$, Fujiwara $Y$, Losung $F$, Mangindaan RE, De Voogd NJ, Takeya M, Tsukamoto S. Bastadins, brominated-tyrosine derivatives, suppress accumulation of cholesterol ester in macrophages. Bioorg Med Chem Lett, 2015, 25(22): 5389-5392.

5. Chistiakov DA, Melnichenko AA, Myasoedova VA, Grechko AV, Orekhov AN. Mechanisms of foam cell formation in atherosclerosis. J Mol Med (Berl), 2017, 95(11): 1153-1165.

6. Shao D, Di Y, Lian Z, Zhu B, Xu X, Guo D, Huang $Q$, Jiang $C$, Kong J, Shi J. Grape seed proanthocyanidins suppressed macrophage foam cell formation by miRNA9 via targeting ACAT1 in THP-1 cells. Food Funct, 2020 11(2): 1258-1269.

7. Zhang X, Li J, Luo S, Wang M, Huang Q, Deng Z, De Febbo C, Daoui A, Liew PX, Sukhova GK, Metso J, Jauhiainen M, Shi GP, Guo J. IgE Contributes to Atherosclerosis and Obesity by Affecting Macrophage Polarization, Macrophage Protein Network, and Foam Cell Formation. Arterioscler Thromb Vasc Biol, 2020, 40(3): 597-610.

8. Lu J, Chen X, Xu X, Liu J, Zhang Z, Wang M, Li X, Chen $H$, Zhao $D$, Wang J, Zhao D, Cong D, Li X, Sun L. Active polypeptides from Hirudo inhibit endothelial cell inflammation and macrophage foam cell formation by regulating the $L O X-1 / L X R-\alpha / A B C A 1$ pathway. Biomed Pharmacother, 2019, 115(108840.

9. Wu T, Peng $Y$, Yan $S$, Li $N$, Chen $Y$, Lan $T$. Andrographolide Ameliorates Atherosclerosis by Suppressing Pro-Inflammation and ROS GenerationMediated Foam Cell Formation. Inflammation, 2018 , 41(5): 1681-1689.

10. Li C, Zhang M, Dai Y, Xu Z. MicroRNA-424-5p regulates aortic smooth muscle cell function in atherosclerosis by blocking APOC3-mediated nuclear factor-kB signalling pathway. Exp Physiol, 2020, 105(6): 1035-1049.

11. Becker AM, Cunha HP, Lindenberg AC, De Andrade F, De Carvalho T, Boaventura BCB, Da Silva EL. SprayDried Yerba Mate Extract Capsules: Clinical Evaluation and Antioxidant Potential in Healthy Individuals. Plant Foods Hum Nutr, 2019, 74(4): 495-500.

12. Correa VG, De Sá-Nakanishi AB, Gonçalves GA, Barros L, Ferreira I, Bracht A, Peralta RM. Yerba mate aqueous extract improves the oxidative and inflammatory states of rats with adjuvant-induced arthritis. Food Funct, 2019, 10(9): 5682-5696

13. Bernardi A, Ballestero $P$, Schenk $M$, Ferrario $M$, Gómez G, Rivero R, Avale E, Taravini I, Gershanik O, Guerrero $S$, Ferrario JE. Yerba mate (Ilex paraguariensis) favors survival and growth of dopaminergic neurons in culture. Mov Disord, 2019, 34(6): 920-922.

14. Yu S, Yue S, Liu Z, Zhang T, Xiang N, Fu H. Yerba mate (llex paraguariensis) improves microcirculation of volunteers with high blood viscosity: a randomized, double-blind, placebo-controlled trial. Exp Gerontol, 2015, 62(14-22).

15. Gao H, Liu Z, Wan W, Qu X, Chen M. Aqueous extract of Yerba Mate tea lowers atherosclerotic risk factors in a rat hyperlipidemia model. Phytother Res, 2013, 27(8): 1225-1231.

16. Yan J, Liu A, Fan H, Qiao L, Wu J, Shen M, Lai X, Huang J. Simvastatin Improves Behavioral Disorders and Hippocampal Inflammatory Reaction by NMDAMediated Anti-inflammatory Function in MPTP-Treated Mice. Cell Mol Neurobiol, 2020, 40(7): 1155-1164.

17. Koubaa-Ghorbel F, Chaâbane M, Turki M, Makni-Ayadi F, El Feki A. The protective effects of Salvia officinalis essential oil compared to simvastatin against hyperlipidemia, liver, and kidney injuries in mice submitted to a high-fat diet. J Food Biochem, 2020, 44(4): e13160.

18. Hofmann A, Brunssen C, Wolk S, Reeps C, Morawietz H. Soluble LOX-1: A Novel Biomarker in Patients With Coronary Artery Disease, Stroke, and Acute Aortic Dissection. J Am Heart Assoc, 2020, 9(1): e013803.

19. Singh S, Gautam AS. Upregulated LOX-1 Receptor: Key Player of the Pathogenesis of Atherosclerosis. Curr Atheroscler Rep, 2019, 21(10): 38.

20. Ding Z, Pothineni NVK, Goel A, Lüscher TF, Mehta JL. PCSK9 and inflammation: role of shear stress, proinflammatory cytokines, and LOX-1. Cardiovasc Res, 2020, 116(5): 908-915.

21. Cai $X$, Zhang $H$, Shi $H$, Zhang $C, X u N$. Purification Process of Polyphenols Group in llex 523 paraguariensis Based on Fingerprint. Herald of Medicine, 2018, 37(02): 231-235.

22. Jin P, Cong S. LOX-1 and atherosclerotic-related diseases. Clin Chim Acta, 2019, 491(24-29).

23. Maguire EM, Pearce SWA, Xiao Q. Foam cell formation: A new target for fighting atherosclerosis and cardiovascular disease. Vascul Pharmacol, 2019, 112(54-71)

24. Wang YT, Wang YH, Ma YT, Fu ZY, Yang YN, Ma X, Li $X M$, Adi D, Liu F, Chen BD. ACAT-1 gene polymorphism is associated with increased susceptibility to coronary artery disease in Chinese Han population: a casecontrol study. Oncotarget, 2017, 8(51): 89055-89063.

25. Gao S, Wang X, Cheng D, Li J, Li L, Ran L, Zhao S, Fan J, Liu E. Overexpression of Cholesteryl Ester Transfer Protein Increases Macrophage-Derived Foam Cell Accumulation in Atherosclerotic Lesions of Transgenic Rabbits. Mediators Inflamm, 2017, 2017(3824276).

26. Hu WN, Duan ZY, Wang Q, Zhou DH. The suppression of ox-LDL-induced inflammatory response and apoptosis of HUVEC by IncRNA XIAT knockdown via regulating miR-30c-5p/PTEN axis. Eur Rev Med Pharmacol Sci, 2019, 23(17): 7628-7638.

27. Ye J, Wu Y, Guo R, Zeng W, Duan Y, Yang Z, Yang L. miR-221 Alleviates the Ox-LDL-Induced Macrophage Inflammatory Response via the Inhibition of DNMT3b-

Trop J Pharm Res, September 2021; 20(9): 1922 
Mediated NCoR Promoter Methylation. Mediators Inflamm, 2019, 2019(4530534).

28. Wang TT, Wang XM, Zhang XL. Circulating Vascular Cell Adhesion Molecule-1 (VCAM-1) and Intercellular Adhesion Molecule-1 (ICAM-1): Relationship with carotid artery elasticity in patients with impaired glucose regulation (IGR). Ann Endocrinol (Paris), 2019, 80(2): 72-76.
29. Hoffmann A, Ebert $T$, Klöting $N$, Kolb M, Gericke M, Jeromin $F$, Jessnitzer $B$, Lössner $U$, Burkhardt $R$, Stumvoll M, Fasshauer M, Kralisch S. Leptin decreases circulating inflammatory IL-6 and MCP-1 in mice. Biofactors, 2019, 45(1): 43-48.

30. Su J, Zhou H, Liu X, Nilsson J, Fredrikson G N, Zhao M. oxLDL antibody inhibits $M C P-1$ release in monocytes/macrophages by regulating $\mathrm{Ca}\left({ }^{2+}\right) / \mathrm{K}\left({ }^{+}\right)$ channel flow. J Cell Mol Med, 2017, 21(5): 929-940. 